\title{
Research into the warm compaction of metal powders
}

\author{
Radu MURESAN \\ Technical University of Cluj-Napoca \\ Radu.Muresan@stm.utcluj.ro
}

Keywords: Metal powders, Warm compaction, Sintering.

\begin{abstract}
The technological method of warm powder compaction is similar to that of axial die compaction, except that both the powder and the die must be heated to a temperature between 100 and $160^{\circ} \mathrm{C}$. This temperature range was chosen for two reasons, i.e.: at temperatures below $100^{\circ} \mathrm{C}$ the effect is negligible, as the phenomena accompanying compaction are identical to those accompanying cold compaction. At temperatures above $160{ }^{\circ} \mathrm{C}$ the risk of particle oxidation increases, although there also is a positive aspect when exceeding such temperature, which is the facilitation of the process of lubricant elimination from the powder mass. The method ensures that the density of the compacts is over $99 \%$ of the theoretical density of the used powder mixtures. This paper intends to present a comparative study of the behaviour of the DensmixTM powder during cold and warm compaction.
\end{abstract}

\section{Introduction}

The warm compaction technique was proposed by the Höganäs Corporation in the U.S. at the beginning of the ' $90 \mathrm{~s}$, and since then it has received more and more attention. This technique can provide high density as compared to the classical compaction techniques. Generally, raw density in the case of warm compaction is influenced by a large number of plastic deformations, which are due to a decrease in the particles' compressive strength [2, 3]. Nevertheless, the main densification mechanism in the case of warm compaction is based on the plastic deformation of the particles. Since it was introduced, a decade ago, warm compaction has become increasingly popular, and it is now used extensively in the manufacture of high strength components. Besides the increase in density, it also results in high strength of raw materials and substantially increased lubrication of the die walls. The subsequent advantages were also used by combining warm compaction with other operations, such as mechanical processing of raw materials, high temperature sintering, sinterforging, surface densification, etc.

The main performance of this technology consists of the design of the powder mixture, the powder heating system and the used equipment. The good properties of the parts made by compaction at certain temperatures represent the success of mass production; this is also made possible by the use of adequate lubricants in the mixtures. Densmix ${ }^{\mathrm{TM}}$ type powders, which were especially designed for warm compaction. The subsequent advantages of the properties of such powders consist in the improvement of certain parameters, such as: dimensional variation, mass variation and specimen consistency.

Warm compaction is characterized by the heating to a temperature of approx. $150{ }^{\circ} \mathrm{C}$. The mixtures designed for warm compaction may be based on any iron or steel powder, as well as alloyed steel powder. The lubricant is optimised to work at high temperatures at $0.6 \%$ content [1].

Warm compaction was introduced onto the market in 1994 and quickly gained ground as an effective method for the manufacture of high density parts used in different applications. Over 150 different components are currently developed and produced. The most commonly used parts that

Content from this work may be used under the terms of the Creative Commons Attribution 3.0 license. Any further distribution of this work must maintain attribution to the author(s) and the title of the work, journal citation and DOI. Published under license by Materials Research Forum LLC. 
have been manufactured so far are different types of cogwheels for hand-held power tools and safety parts for automotive applications. The helical gears for different applications are a fast growing sector of warm compaction.

The weight of the parts ranges between 5 and 105 grams in Europe and Asia, while auto components weighing up to 1100 grams are produced in the U.S. The heating system used in Europe and Asia is the one developed by the Höganäs Company. Within this heating system, the powder is heated by heated oil.

Since it was introduced, warm compaction has gained much experience both in the laboratory, and in the part production [4-6]. The obtained advantages are not only the increase in density, raw strength and the static mechanical properties, but also a number of other favourable factors that will be important for the future growth in the competitiveness of powder metallurgy.

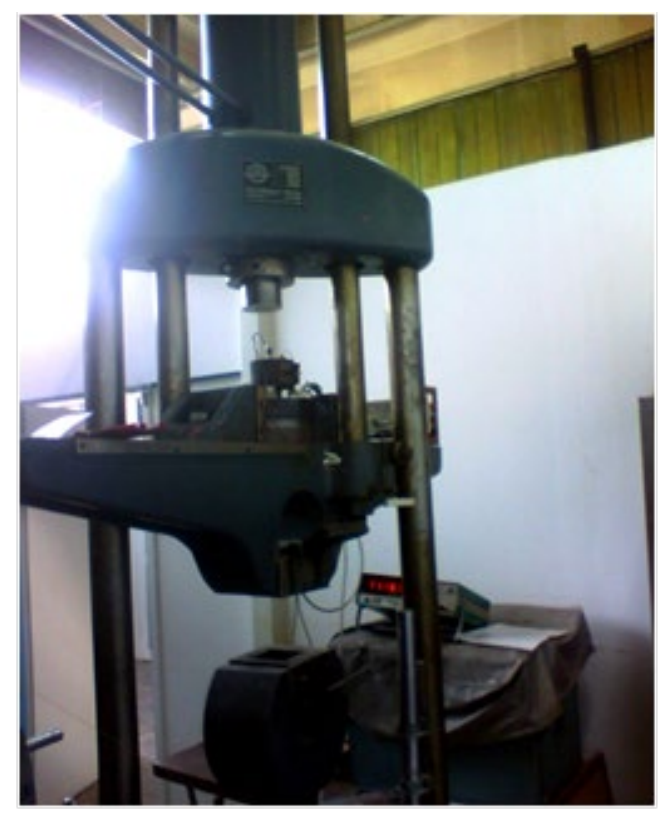

\section{Experimental}

Fig. 1. The warm compaction system.

We conducted experiments on the DensmixTM powder manufactured by the Höganäs $A B$ Company, Sweden, powder which had the following characteristics:

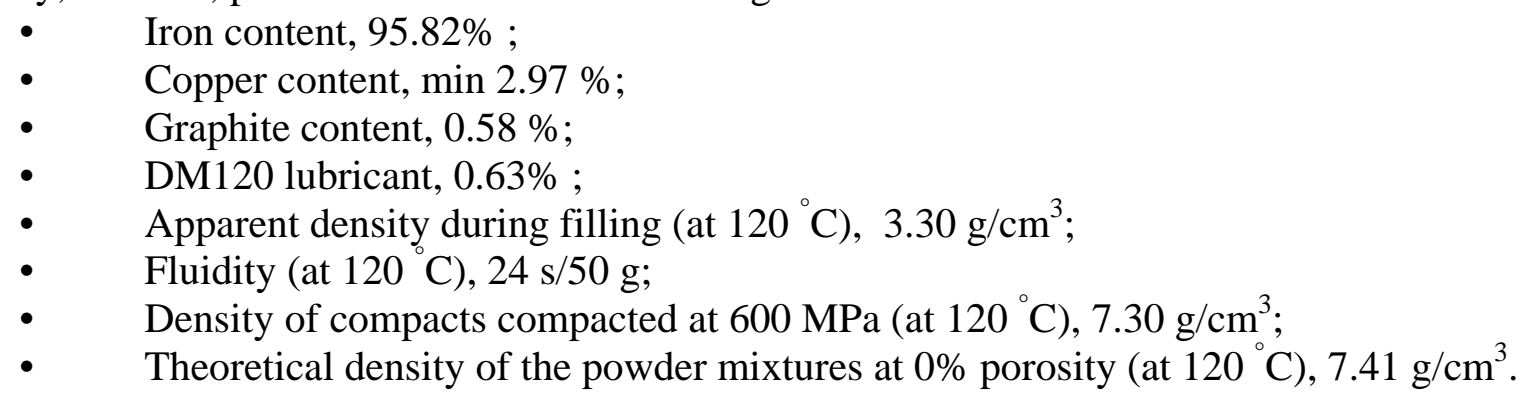

In order to determine the compactibility of the Densmix powder, we made tablets with an area of $1 \mathrm{~cm}^{2}$ by cold compaction and tablets with an area of $0.5 \mathrm{~cm}^{2}$ for warm compaction. Warm compaction was performed at the following temperatures: $80{ }^{\circ} \mathrm{C}, 100{ }^{\circ} \mathrm{C}, 120{ }^{\circ} \mathrm{C}, 140{ }^{\circ} \mathrm{C}$, and 160 ${ }^{\circ} \mathrm{C}$. For warm compaction purposes, the die and the powder were heated together using an electrical resistance heating device, Fig. 1. The powder was compacted in the die, and was kept for 
approximately 20 seconds at the chosen temperature at pressures of 100, 200 and $300 \mathrm{MPa}$, respectively. For the comparative study, the same powder type was cold compacted at the following pressures: 200, 300, 400, 500, and $600 \mathrm{MPa}$.

After sintered at a temperature of $1120{ }^{\circ} \mathrm{C}$, in a belt oven in endogas atmosphere. The specimens were kept at the sintering temperature for 30 minutes. The density after sintering was determined by the hydrostatic weighing method. Resilience was determined by the Charpy method, and hardness was determined by the Brinell method.

Based on the obtained data, we plotted the variation curves of apparent density, density after sintering, resilience and hardness as functions of the temperature and the compaction pressure; the curves are shown in Fig. 2, 3, 4, 5 and 6 respectively.

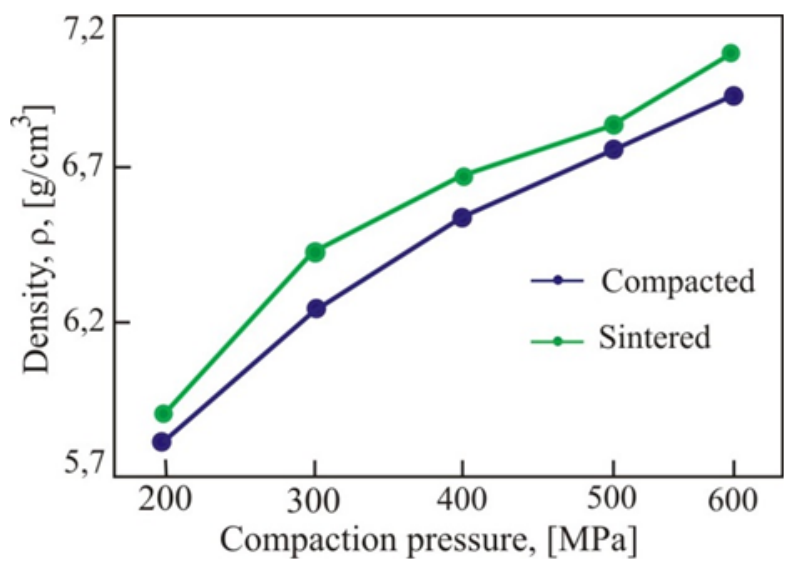

Fig. 2. Variation in the density of the Desmix $^{\mathrm{TM}}$ powder after compaction and sintering.

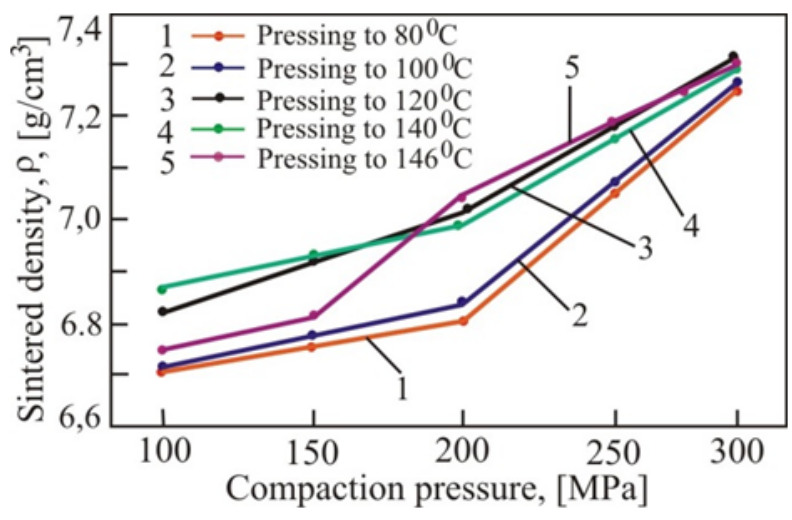

Fig. 4. Variation in the density of the warm compacted and sintered Desmix ${ }^{\mathrm{TM}}$ powder.

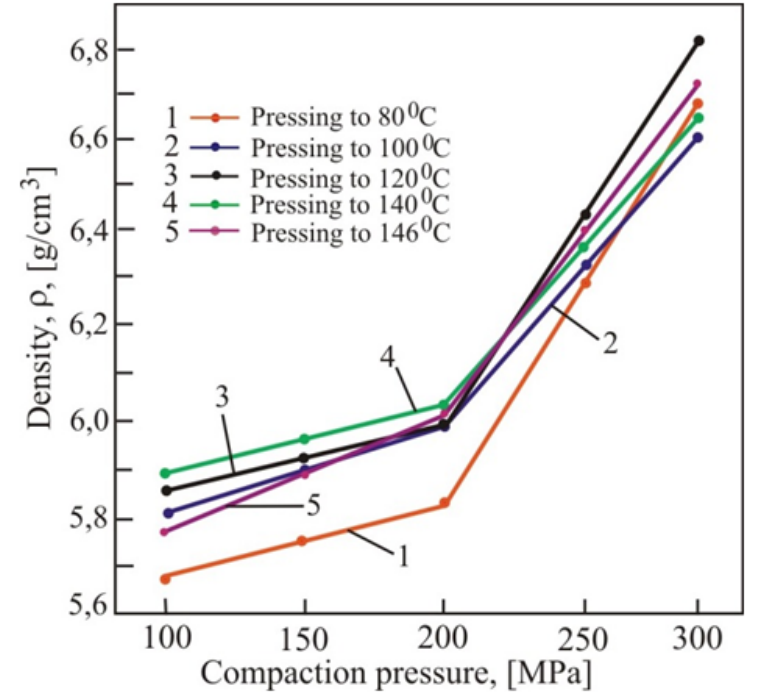

Fig. 3. Variation in the density of the Desmix $^{\mathrm{TM}}$ powder as a function of the compaction temperature.

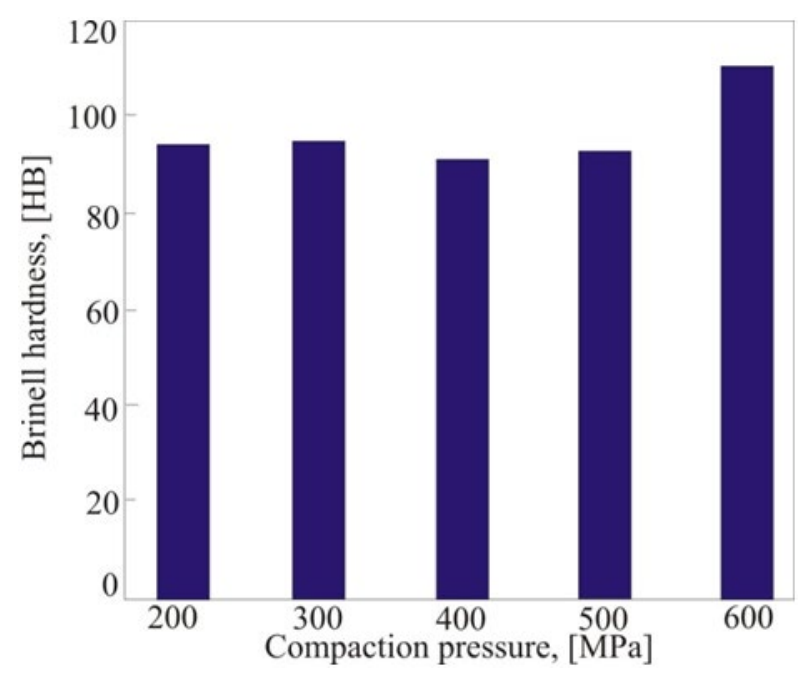

Fig. 5. Variation in the hardness of the cold compacted specimens as a function of the compaction pressure. 


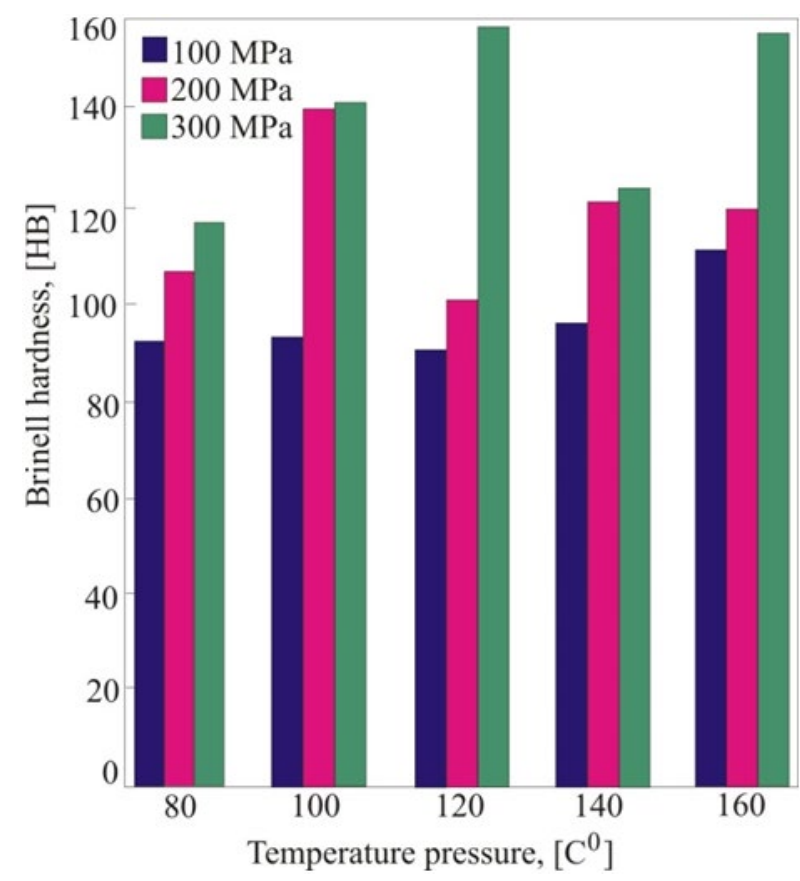

Fig. 6. Variation in specimen hardness after sintering as a function of the compaction pressure and temperature.

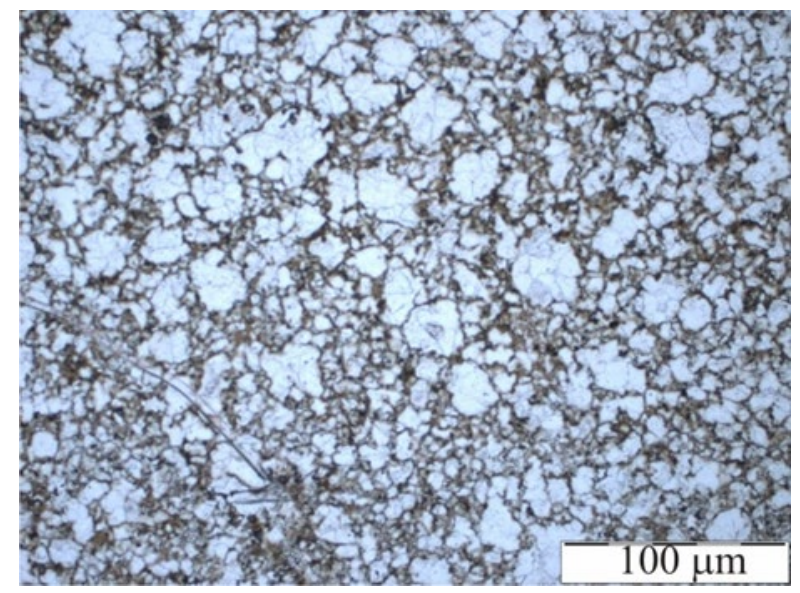

Fig. 7. Microstructure of the compacted and sintered Densmix ${ }^{\mathrm{TM}}$ specimen.

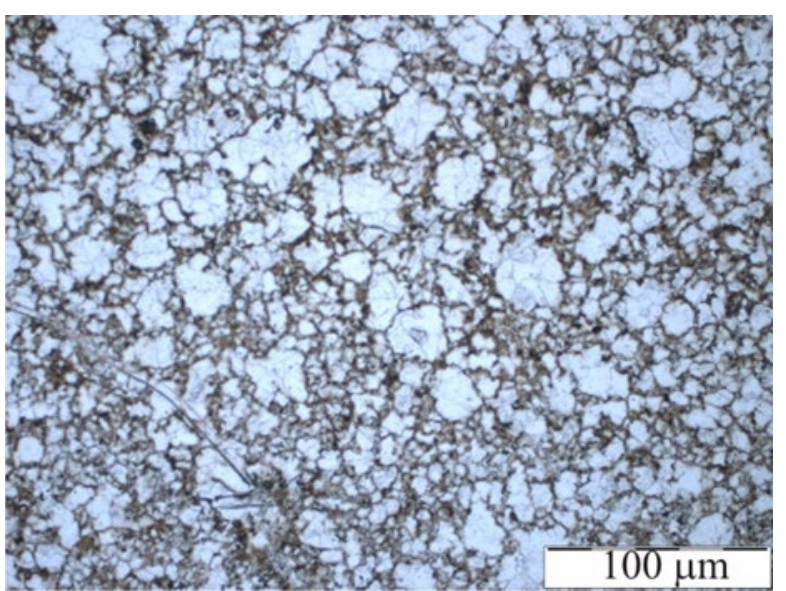

Fig. 7. Microstructure of the compacted and sintered Densmix ${ }^{\mathrm{TM}}$ specimen.

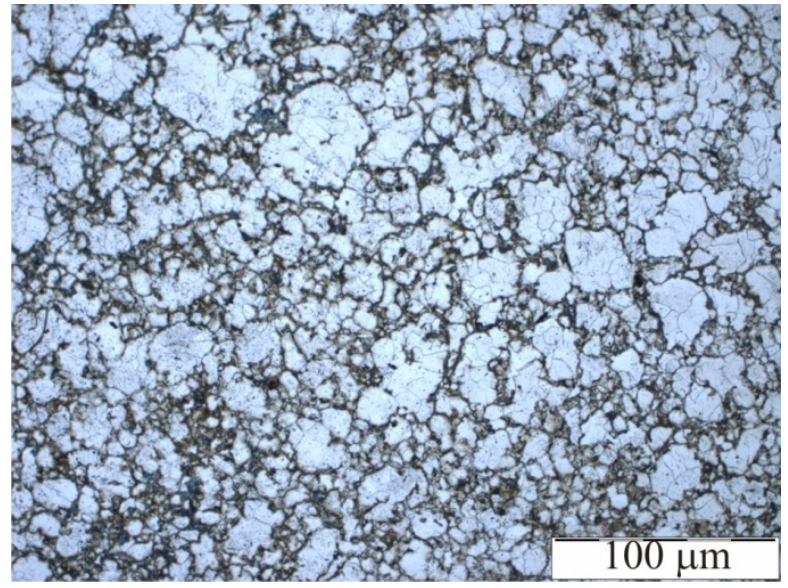

Fig. 8. Microstructure of the specimen compacted at a temperature of $80{ }^{0} \mathrm{C}$ and sintered.

Due to the complexity of the matter, we chose to study these properties, since they are the most commonly used in practical applications of warm compacted parts.

The metallographic study was conducted on all the specimens from which microstructures were selected for the specimens compacted at the temperatures of 80,120 , and $140{ }^{\circ} \mathrm{C}$, and sintered, shown in Fig. 7, 8 and 9. In Fig. 7 we notice a finer structure, with larger agglomerations of solid 
solution and nonhomogeneous compactness. In Fig. 8 we notice that compactness increases gradually, the grains become smaller and smaller, and the agglomerates of solid solution become increasingly larger, while porosity decreases. Fig. 9 shows large agglomerates of solid solution surrounded by pearlitic structural constituents, isolated pores, but no major change from the specimens compacted at $120^{\circ} \mathrm{C}$.

\section{Summary}

Based on the experimental research conducted on the DensmixTM powder and the processing of the obtained experimental data, we concluded that the best mechanical properties are obtained by warm compaction at a temperature of $120{ }^{\circ} \mathrm{C}$ and a compaction pressure of $300 \mathrm{MPa}$.

The main densification mechanism in the case of warm compaction is based on the plastic deformation of particles. Consequently, the powder mixture intended for warm compaction must satisfy the following conditions:

- The shape of the particles must be spherical, when the friction is minimal and the rotation of particles is favourable, but, from the compactibility perspective, the surface of the powder has a defined rugosity.

- The grain distribution of the powder mixture must be similar in size.

- The basic powder for warm compaction must be a partially alloyed iron powder, which provides good compactibility to the mixture.

- In order to satisfy the sintering requirements, the lubricant must have a wide decay temperature range, and the decay must form volatile monomolecular chemicals, which have a favourable effect on the elimination of defects, such as void spaces, cracks and dimensional compact expansion during sintering, and last but not least prevent the formation of residual carbon, which precludes us from controlling the carbon content in the compact.

Particle rearrangement is one of the densification mechanisms in the case of warm compaction. However, plastic deformation of particles plays an important role in particle rearrangement.

\section{References}

[1] U. Engström, B. Johansson: Experiences with Warm Compaction of Densmix ${ }^{\mathrm{TM}}$ Powders in the Production of Complex Parts, Proceedings of Powder Metallurgy World Congress 2000, Kyoto, Japan, November 2000.

[2] J. Yi, T. Ye, Y. Peng, Effects of warm compaction on mechanical properties of sintered P/M steels, Journal of Central South University of Technology 14 (2001) 447-451. https://doi.org/10.1007/s11771-007-0087-z

[3] D.Y. Yoon, S.L.K.Y.Eun, Y.S. Kim, Densification Mechanism of warm Compaction for IronBased Powder Materials, Materials Science Forum, 534-536 (2007) 261-264. https://doi.org/10.4028/www.scientific.net/MSF.534-536.261

[4] G.F. Bocchini, The Warm Compaction Process. Basics, Advantages and Limitations, SAE Transactions, Society of Automotive Engineers, 107 (1998) 225-236.

[5] U. Engström, B. Johansson, P. Knutsson and H Vidarsson: Material Properties and Process Robustness obtained with Warm Compaction of Improved Densmix ${ }^{\mathrm{TM}}$ Powders, Proceedings of Powder Metallurgy World Congress 2002, Orlando, USA, June 2002.

[6] http://www.lindemetall.se/produkter/slot heater_e.htm. 